\title{
Cover crop and tillage intensities alter ground-dwelling arthropod communities during the transition to organic production
}

\author{
Randa Jabbour ${ }^{1}$, Tara Pisani-Gareau², Richard G. Smith ${ }^{3}$, Christina Mullen ${ }^{4}$ and \\ Mary Barbercheck ${ }^{4 *}$ \\ 'Current address: Department of Plant Sciences, University of Wyoming, Laramie, WY 82071, USA. \\ ${ }^{2}$ Current address: Department of Earth and Environmental Sciences, Boston College, Chestnut Hill, MA 02467, \\ USA. \\ ${ }^{3}$ Department of Natural Resources and the Environment, University of New Hampshire, Durham, NH 03824, USA. \\ ${ }^{4}$ Department of Entomology, 501 ASI, Penn State University, University Park, PA 16802, USA. \\ *Corresponding author: meb34@psu.edu
}

\begin{abstract}
We conducted a cropping systems experiment in central Pennsylvania, USA, to determine the effects of initial cover crop species and soil management on the abundance and composition of the ground-dwelling arthropod community. We hypothesized that we would detect legacy effects of the cover crops planted in year 1 of a 3-yr crop sequence on the arthropod community in the subsequent $2 \mathrm{yrs}$, and that these effects would be influenced by the intensity of tillage. We compared four systems in a factorial combination of perennial sod and legumes or annual cereal grain and legume as initial cover crops and moldboard or chisel plow tillage implemented in soybeans followed by maize in the subsequent 2 yrs. The entire experiment was initiated twice in adjacent locations, starting in 2003 (Start 1) and 2004 (Start 2). We quantified soil arthropod activity-density and community composition and identified all arthropods to order or family, and the ground and tiger beetles (Coleoptera: Carabidae) to species. In Start 1, but not Start 2, arthropod activity-density increased with each year following implementation of organic management. We observed few legacy effects of cover crop or tillage intensity on arthropod activity-density. The composition of the soil arthropod community was primarily defined by the initial cover crop in the first year, and by the interaction between cover crop and tillage intensity in the second and third year. A legacy effect associated with a yr-1 cover crop of cereal rye was observed for Scarabaeidae beetles and Formicidae (ants) in yr 2 and Carabidae beetles in yr 3 of Start 1, but not Start 2. Weed indicators contributed significantly to the variation in the soil arthropod community that was explained by the environment in yr 2 in Start 1, and in yr 3 in both Starts. Our observations support the concept that both immediate and legacy effects of management shape arthropod communities during the organic transition period, suggesting that transitioning systems could be managed in ways that conserve or enhance natural enemy populations.
\end{abstract}

Key words: organic agriculture, organic transition, cover crop, Carabidae, arthropod community composition, weed-arthropod interactions

\section{Introduction}

Biodiversity tends to be higher in organic cropping systems in comparison with conventional systems, and this holds true for arthropod diversity (Bengtsson et al., 2005; Clark et al., 2006; Lundgren et al., 2006; Menalled et al., 2007; Bourassa et al., 2008; Shennan, 2008; Crowder et al., 2010, 2012). Gains in biodiversity after transition to organic production are principally attributed to increased organic matter inputs into soil, a cessation of synthetic agrochemical applications, and increases in plant diversity. The effects of specific management decisions made during the transition to organic production, such as the type and timing of tillage, cover crop species, year of initiation of transition and cash crop species on insect communities is less well studied. The transition from conventional to organic practices can be a particularly challenging time for growers when lower yields are typically expected (Mäder et al., 2002; De Ponti et al., 2012) and organic price premiums are not 
available. Thus, information on the effects of specific practices within organic management may help to reduce risk during and after the transition.

Both potential pest and beneficial arthropods can contribute to increased diversity in organic systems. In organic agronomic cropping systems, where organically approved materials are often not economical to use, growers primarily rely on cultural practices and natural enemies to manage arthropod pests, and it is critical to build and conserve natural enemy communities to help prevent pest outbreaks (Zehnder et al., 2007; Birkhofer et al., 2008). The 3-yr transition period from nonorganic to organic production can be especially challenging from a pest management perspective because the diverse trophic interactions that can stabilize pest populations take time to develop after ceasing the use of synthetic chemical pesticides. In the USA, farmers transitioning from non-organic to certified organic crop production report that weeds and insect pests are among their top challenges, in large part because synthetic pesticides are not allowed (OFRF, 1998). Increases in pest populations that occur during this period may lead to longer-term challenges following organic certification. Accordingly, a critical question to ask is if management practices that are implemented during the initial phases of the transition period have persistent effects on arthropod communities, particularly beneficial insects. If yes, then how do management practices interact to alter these legacy effects? Although these questions have been examined relative to weedy pests (e.g., Maxwell et al., 2007; Smith et al., 2009), little attention has been paid to arthropods.

Farmers employ a range of soil and crop management practices during the transition to organic production to balance soil quality, pest management and crop productivity. Without the use of herbicides, transitioning farmers typically rely on tillage to control weeds and incorporate animal and green manures. However, frequent or intensive tillage can result in an overall decrease in soil quality, particularly by lowering soil organic matter concentrations from the labile fraction (Cambardella and Elliott, 1992; Gregorich and Janzen, 1996), and can reduce the functional capacity of a soil. Soil faunal biomass often drops with use of inversion tillage, and intensive or frequent tillage can suppress beneficial soil organisms (Stinner and House, 1990; Lundgren et al., 2006). The reliance of organic growers on inversion tillage can thus be in conflict with the goals of conservation of soil, energy, biodiversity, and profitability in organic systems (Mirsky et al., 2012; Carr et al., 2013; Cavigelli et al., 2013). In response, some organic farmers are experimenting with practices to reduce tillage and incorporate cover crops that have multiple purposes, for example, to control erosion, suppress weeds and contribute to soil fertility and quality.

Tillage can have variable effects on soil arthropod fauna. The degree of soil disturbance, and environmental conditions, e.g., amount of crop residue, soil moisture and temperature, associated with conservation tillage may favor an increase in crop damage from some herbivorous pests, while damage from others may decrease (Stinner and House, 1990; Zehnder et al., 2007). Inversion tillage can be beneficial when it disrupts the life cycle of insect pests, exposes them to predators, destroys crop debris that serve as overwintering sites, or distributes entomopathogens throughout the soil profile (Stinner and House, 1990; Zehnder et al., 2007; Jabbour and Barbercheck, 2009). Some predators may be adapted to the high disturbance and open soil environment of tilled systems; for example, some carabid beetles, such as Poecilus spp. and Pterostichus melanarius (Illiger) occur in higher numbers in inversion tillage systems in comparison with conservation tillage systems (Hatten et al., 2007; Menalled et al., 2007).

Reduction in tillage frequency or intensity can result in changes in habitat that can affect the activity-density, species richness and community composition of arthropods through provision of shelter and favorable microclimate and animal and floral food resources (Pullaro et al., 2006; Pereira et al., 2010; Mccravey and Lundgren, 2011; Diehl et al., 2012). The resources provided by living and dead cover crops, weeds and other organic amendments may increase suppression of pests by promoting competitive, predaceous, or antagonistic organisms that contribute to the resistance of a system to pest outbreak (Carmona and Landis, 1999; Menalled et al., 2000; Lundgren et al., 2006). Reduced tillage systems can favor species that prefer a closed habitat, higher organic matter residue and a diverse decomposer community for prey (Lundgren et al., 2006).

Ground and tiger beetles (Carabidae: Coleoptera) are important in agricultural systems because of their role as predators of pest arthropods and slugs (Kromp, 1999) and as consumers of weed seeds (Honek et al., 2003; Menalled et al., 2007; Bohan et al., 2011). Carabid beetle diversity increases where tillage is reduced and the range of microhabitats that supports preferences of different carabid species increases (Honek and Jarosik, 2000; Purvis et al., 2001; Melnychuk et al., 2003; Purtauf et al., 2005; O'Rourke et al., 2008; Diehl et al., 2012). Furthermore, reduced tillage systems that have low soil disturbance and retain soil moisture benefit ground-dwelling predators during the larval stage when they are less mobile and more sensitive to low soil moisture (Lundgren et al., 2005).

The type of cash or cover crop affects ground-dwelling arthropods via crop-related resources such as seeds, pollen, biomass and canopy structure, which affects soil moisture and temperature. Epigeal arthropods are more abundant in cover crops than in bare control or fallow treatments (Lundgren et al., 2006; Prasifka et al., 2006; Pullaro et al., 2006; Shearin et al., 2008; Lundgren and Fergen, 2011). Crop type has a stronger effect on Carabidae richness, diversity and composition than management treatments (e.g., chemical inputs and tillage), 
which indicates that habitat suitability for soil dwelling predators may change from year to year depending on many factors (Bourassa et al., 2008). However, legacy effects on arthropod communities may also occur if the cropping system has long-lasting effects on weed-related resources (e.g., seeds and pollen), herbivorous prey, or the microclimate (Diehl et al., 2012).

This research is part of a larger project to measure the effects of management approaches in the transition from non-organic to organic production on several characteristics in a typical agronomic cropping system, including weeds (Smith et al., 2009, 2011), soil quality (Lewis et al., 2011), entomopathogens (Jabbour and Barbercheck, 2009) and crop productivity and economics (Smith et al., 2011). For the research reported here, we hypothesized that during the 3-yr transition, activity-density, diversity and community composition of ground dwelling arthropods and specifically Carabidae beetles will differ according to initial cover crop, and where conservation tillage, in comparison with inversion tillage, is employed. We addressed three questions: First, do ground-dwelling arthropod communities differ between annual and perennial cover crops in the first year of the 3-yr organic transition period? Secondly, do these effects persist during subsequent phases of the organic transition period? Thirdly, are environmental conditions created by management associated with the nature and magnitude of any current year or legacy effects on the arthropod community?

\section{Materials and methods}

\section{Site}

The field experiment was conducted at the Russell E. Larson Agricultural Research Center near Rock Springs, PA ( $40^{\circ} 43^{\prime} \mathrm{N}, 77^{\circ} 55^{\prime} \mathrm{W}, 350 \mathrm{~m}$ elevation). The climate is continental with $975 \mathrm{~mm}$ mean annual precipitation and mean monthly temperatures ranging from $3^{\circ} \mathrm{C}$ (January) to $21.6^{\circ} \mathrm{C}$ (July). Soils at the site are shallow, well drained lithic Hapludalfs formed from limestone residuum (Braker, 1981). The dominant soil type at this location is a Hagerstown silt loam (fine, mixed, semiactive, mesic, Typic Hapludalf). Soil texture in our experimental field was predominantly clay loam with spatial variability in silt (range of 39.9-54.7\%) and sand (14.0-27.0\%) content across the field. Previously, the site had been conventionally cropped with a tomato-wheat rotation, with tomato preceding the transition experiment.

\section{Experimental design and field operations}

The 3-yr experiment was managed organically, and culminated with organic certification. During these $3 \mathrm{yrs}$, fields were in cover crops in rotation yr 1, soybeans in yr 2 and maize in yr 3 . The $2 \times 2$ factorial design crossed two tillage approaches with $2 \mathrm{yr}-1$ cover crops. The experiment was established twice, first in autumn 2003 and again in autumn 2004 in an adjacent field (the two experimental Starts are hereafter referred to as 'S1' and 'S2'), in a randomized complete block design with four replicates in each Start. Each treatment plot measured $24 \times 27 \mathrm{~m}^{2}$ $(0.065 \mathrm{ha})$. The site was surrounded by $>7 \mathrm{~m}$ of routinely mown grassy border. Feed-grade soybean [Glycine max (L.) Merr., late Group III maturity, Pioneer 93B87] and maize (Zea mays L., Pioneer 36B08) were planted in all treatment plots in rotation yrs 2 and 3, respectively, at a row spacing of $76 \mathrm{~cm}$.

$\mathrm{S} 1$ and $\mathrm{S} 2$ were managed similarly, with treatments in $\mathrm{S} 2$ off-set by $1 \mathrm{yr}$ relative to the S1 (Supplementary Table 1). In the year before initiating S2, the entire S2 field was managed organically with a mixed cover crop of timothy (Phleum pratense L.), oat (Avena sativa L.) and medium red clover (Trifolium pratense L.). To ensure relevance to organic feed grain cropping systems typical of the region, an advisory board composed of local growers helped to guide the crop sequence and management decisions throughout the experiment. Thus, cover crops were selected to provide immediate economic returns during the transition period if harvested for grain, straw, or forage, while providing agroecological benefits such as improved soil quality, erosion control and weed suppression. All management practices followed USDA National Organic Program guidelines (http://www.ams. usda.gov/NOP). For a timeline and detailed description of all field operations, see Smith et al. (2011).

Cover crop treatments. The two cover crop treatments were initiated in the fall preceding rotation $\mathrm{yr} 1$, and maintained over spring and summer of yr 1 (2003-04 in S1; 2004 05 in S2). In one cover-crop treatment (RYE), cereal rye (Secale cereale L. cv. Aroostook) was planted in the fall and managed for grain production in the summer of yr 1. After harvest of the cereal rye, hairy vetch (Vicia villosa Roth) was planted in the fall of yr 1 and killed in the following spring. In the second cover crop treatment (TIM), oat (Avena sativa L.) was planted in the fall, followed by a mixture of timothy (Phleum pratense L.) and red clover (Trifolium pratense L.) in the spring of rotation yr 1, and managed for sod formation and forage production.

Tillage treatments. The two tillage treatments were full inversion (FT, moldboard plow-based) and reduced tillage (RT, chisel plow- and field cultivator-based). In the RYE cover crop treatment, the hairy vetch was killed either by moldboard plow (FT treatment) or mechanical roller-crimper (RT treatment). The TIM treatment was first tilled in the spring of rotation yr 2, prior to planting soybean. Through the remainder of the experiment, primary tillage in the FT treatment was accomplished with a moldboard plow and in the RT treatment with a chisel plow. Rotary hoe and field cultivator use was the same in both tillage treatments. In S2, an additional cultivation occurred in maize in RT treatments to improve perennial weed control.

Arthropod sampling. We used a pitfall sampling method to assess the activity-density of ground-dwelling arthropods 
(Morrill, 1975). Pitfall traps measure activity-density because the probability of capturing an organism is a function of both population density and activity level. Pitfall traps consisted of $946 \mathrm{~mL}$ plastic deli containers $(114 \mathrm{~mm}$ mouth diameter, $129 \mathrm{~mm}$ deep) with sample cups $(87 \mathrm{~mm}$ mouth diameter, $60 \mathrm{~mm}$ deep) and lids. Three traps were randomly placed in each plot, at least $3 \mathrm{~m}$ from plot edges, and buried so that the tops of the traps were flush with the soil surface. Sample cups were filled with ethylene glycol $(40 \mathrm{~mL})$ and placed in the bottom of the larger container. Funnels made from the tops of polyethylene 2 liter bottles were placed into the opening of the trap to exclude larger organisms. The traps were opened for $72 \mathrm{~h}$, and then the contents were collected, traps were removed from the field, and contents processed in the laboratory. Pitfall traps were collected in 2004 (June 21, August 6 and October 7), 2005 (June 20, July 28 and October 21), 2006 (July 3, August 21 and November 2), and 2007 (July 2 and November 1) (Supplementary Table 1). S1 was sampled from 2004 to 2006, and the S2 was sampled from 2005 to 2007.

Arthropods were removed from the ethylene glycol and placed in scintillation vials ( $20 \mathrm{~mL}$ volume) filled with 19 $\mathrm{mL}$ of $80 \%$ ethanol plus $1 \mathrm{~mL}$ glycerol for storage until they could be identified to order or family. Adult ground and tiger beetles (Carabidae) were sorted, pinned and identified to species. Species identification was performed using several taxonomic keys (Downie and Arnett, 1996; Ciegler and Morse, 2000; Marshall, 2006) and voucher specimens from previous studies (Leslie et al., 2007), and identifications were confirmed by Mr. Robert Davidson (Carnegie Museum of Natural History, Pittsburgh, PA).

\section{Soil analysis}

We sampled soils in each Start four times in each rotation year: May, June-July, August and September-October. On each sampling occasion, three soil samples were collected from random locations at least $3 \mathrm{~m}$ from the edge within each treatment plot. Each sample comprised 15 cores $(2.5 \mathrm{~cm}$ diameter $\times 15.2 \mathrm{~cm}$ deep) collected in a cluster, thoroughly mixed by hand in a bucket, placed into a plastic bag and stored at $4^{\circ} \mathrm{C}$. Permanganate oxidizable ('active C') (Weil et al., 2003; Culman et al., 2012) and soil moisture, measured as matric potential, were analyzed from each sample separately. Values used are averages from each year in sequence. Full soil sampling methods are described in Lewis et al. (2011).

\section{Weed analysis}

As described in Smith et al. (2011), we assessed the effects of the initial cover crop and tillage treatments on the density of weeds that emerged from the existing seed bank each season. Weed densities were assessed by counting all weeds present in five, $0.25 \mathrm{~m}^{2}$ quadrats randomly placed in each treatment plot, at least $3 \mathrm{~m}$ from the edge of the plot. Weed density measurements were made before each disturbance event (i.e., cultivation), if multiple disturbance events occurred within a growing season. Weed density data were summed to determine the cumulative weed density in each plot for each growing season. For analyses and presentation, the data were separated into annual and perennial weed species.

\section{Statistical analysis}

Arthropod activity-density and community composition. Arthropod activity-densities (numbers of arthropods, identified to order or family) were summed over the three pitfall traps per treatment plot for each date, and then averaged across sample dates within each year. The average values summarized over these dates create one datum per treatment replicate per year, representing an activity-density (number of individuals captured/plot/72 h) for each taxon. In univariate analyses, activity-densities were transformed with the formula $\log _{10}(x+1)$ to achieve normality. We used repeated measures split-plot mixed models with PROC MIXED (SAS Institute, 2004) to test whether the activity-density of arthropods differed between annual and perennial cover crops in the first year of the organic transition period, whether the effects persisted in subsequent years and whether tillage mediated the effects of cover crops. Tillage intensity was considered the main plot treatment and initial cover crop the subplot treatment. We accounted for repeated sampling at the same site throughout the experiment by including an autoregressive covariance matrix in the model (Stokes et al., 2000). Data from each experimental Start were analyzed separately. Block was coded as a random variable.

Because the response of an individual taxon to a treatment may not be independent from the response of other taxa in a community or environmental characteristics, we performed a multivariate direct gradient analysis to explore the specific association of the arthropod community with treatments and environmental variables, including soil (Lewis et al., 2011) and weed community characteristics (Smith et al., 2009, 2011) measured during the same time period. Preliminary detrended correspondence analysis using all taxa indicated that community composition gradients were short, therefore, a linear gradient procedure, redundancy analysis (RDA), was performed with 'CANOCO' for Windows version 5.0 (Šmilauer and Lepš, 2014). Experimental factors (tillage, cover crop) were treated as explanatory variables, and block was treated as a covariate. Mean activitydensities of soil arthropods per plot ( $n=3$ traps/plot), and averaged across sample dates in each experimental start and year and occurring in greater than $25 \%$ of samples were included in the RDA. A Monte Carlo permutation option was employed to determine the significance of the first axis and of all canonical axes combined, constrained by block. RDA results are 
displayed graphically with bi-plot scaling focused on centered inter-taxon distances, where symbols depict treatment variables and response variables, including adult soil arthropod taxa, unless designated as larvae, with a fit to the model of at least $20 \%$ are represented as vectors. Efficiency of the first two canonical axes was determined by comparing the overall variation in soil arthropod taxa in the RDA (constrained by cover crop and tillage treatments) with the fraction of variation explained by all environmental variables in a principal components analysis. We used interactive forward selection to determine environmental measures that significantly $\left(P_{\text {adj }}<0.05\right)$ contributed to variation in soil arthropod taxa. Significant environmental variables were projected onto the biplots as passive supplementary response variables (terBraak and Šmilauer, 2012; Šmilauer and Lepš, 2014).

To test whether the community composition of soil arthropods changed significantly in each treatment combination (tillage $\times$ cover crop) between years (time $\times$ treatment), we used principal response curves (PRC), a form of RDA which explores the extent of differences at multiple time steps and among treatments (terBraak and Šmilauer, 2012). Each response curve represents community composition over the temporal trajectory. The sampling dates (yr 1, 2 and 3 in the cropping sequence) are used as covariates, and the interactions between year, tillage regimen and initial cover crop are used as the environmental treatment variables. In both Starts, the TIM $\times \mathrm{RT}$ treatment combination was set as the control, represented by a horizontal line in the PRC diagrams, because it experienced the least frequent and least intensive disturbance from tillage events. The significance of the model was assessed using Monte Carlo simulations with 4999 iterations. We used an inclusion rule that taxa be present in at least $25 \%$ of samples for inclusion in the analysis. In figures, the scores for soil arthropod taxa for which at least $10 \%$ of the variance of the values for that taxon was explained by the ordination space are presented. Higher scores indicate greater percentage variance explained by the ordination space.

Activity-density, diversity and community composition of carabid beetles. To analyze the activity-density and annual accumulated diversity of Carabidae among treatments, we summed the numbers of individuals for each carabid beetle species collected within each replicate of each year. Activity-densities were transformed with the formula $\log _{10}$ $(x+1)$ for analyses. We used non-transformed annual totals of richness and activity-density to calculate diversity measures and to describe the differences among treatments. Because diversity incorporates both species richness and relative proportion of individuals, to assess the effects of experimental treatments on diversity of adult carabid beetles, we used three diversity measures: species richness $(S)$, evenness $\left(E_{\mathrm{var}}\right)$ (Smith and Wilson, 1996) and the Shannon-Wiener Index $\left(H^{\prime}\right)$ (Shannon, 1948). We used repeated measures split-plot mixed models with PROC
MIXED (SAS Institute, 2004) to test whether tillage regimen, initial cover crop, year in sequence and the interactions among fixed effects affected activity-density, species richness, evenness and diversity of carabid beetles captured in pitfall traps. Tukey's mean comparisons were conducted for significant treatments or interactions.

\section{Results}

\section{Arthropod and carabid beetle activity-density}

We collected a total of 155,265 arthropods (Fig. 1) in pitfall traps in the experimental treatment plots. A total of 111,190 were collected during eight sampling events in S1, and 44,075 arthropods were collected during eight sampling events in S2 (Supplementary Table 2). The most commonly collected arthropods were Collembola and Acari, which comprised 81.5 and $15.1 \%$ of the total arthropod activity-density, respectively. We collected 2180 adult Carabidae beetles representing 58 species and comprising $1.4 \%$ of the total arthropod activitydensity (Supplementary Table 3). Approximately $65 \%$ of the carabid beetles collected were from six species, in order of greatest to least activity-density: Poecilus chalcites (Say), Bembidion quadrimaculatum (Say), Harpalus pensylvanicus (DeGeer), Cicindela punctulata (Olivier), Poecilus lucublandus (Say) and Bembidion rapidum (LeConte).

The year in crop sequence affected arthropod activitydensity in both $\mathrm{S} 1\left(F_{2,19.7}=85.04 ; P<0.0001\right)$ and S2 $\left(F_{2,20.8}=14.68 ; P<0.0001\right)$ (Fig. 1$)$. In S1, mean ( \pm standard error) arthropod activity-densities were lowest in yr $1(140.3 \pm 12.7)$, intermediate in yr 2 (283.4 $\pm 23.6)$ and highest in yr $3(657.8 \pm 83.7)$. Differences in mean activity densities in each year were significant (yr 1 versus yr $2, P=0.0002$; yr 1 versus yr $3, P<0.0001$; yr 2 versus yr $3, P=0.0001)$. In general, arthropod activity-densities in S2 were lower than in S1. Mean S2 activity-densities per plot in yrs 1, 2 and 3 were $197.9 \pm$ $9.9,151.6 \pm 7.1$ and $228.7 \pm 15.3$, respectively. In S2, arthropod activity-density in year 1 differed from yr 2 $(P=0.0038)$, but not yr 3 , and activity-density in yr 2 was different from yr $3(P=0.0001)$. In $\mathrm{S} 2$, there was a significant year $\times$ cover crop interaction $\left(F_{2}, 20.8=3.55\right.$; $P=0.0472)$ in which there were no differences due to year in RYE treatments, but activity-densities in TIM treatments were lower in yr 2 than in yr $1(P=0.0025)$ or $3(P=0.0017)$ (Fig. 1).

\section{Effects of cover crops on arthropod activity- density and community composition}

The main effect of cover crop on soil arthropod activitydensity was not significant in S1 or S2 in yrs 1, 2 or 3. Therefore, the hypothesis that the initial cover crop system resulted in lasting legacy effects on general arthropod activity-density was not supported. 


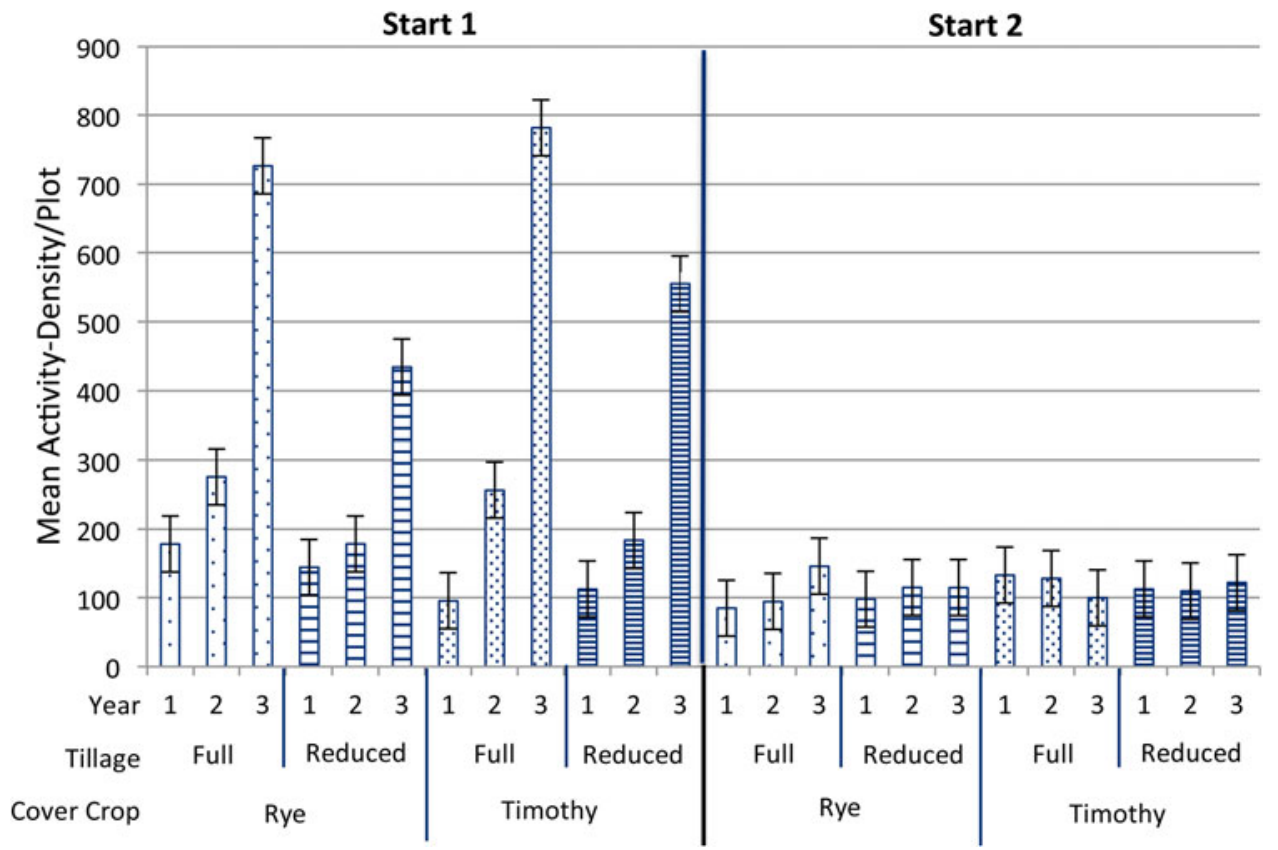

Figure 1. Mean ( \pm standard error) arthropod activity-densities in yrs 1 (cover crop), 2 (soybean) and 3 (maize) in full (FT) and reduced (RT) tillage treatments following a yr-1 cover crop of cereal rye followed by hairy vetch (RYE) or timothy/red clover mixture (TIM) during the 3-yr transition to organic production. The experiment was started in 2003 (Start 1) and repeated in 2004 (Start 2).

In contrast to the general arthropod community, cover crop and interactions with cover crop affected the activitydensity of carabid beetles. Year $\left(F_{2,23}=17.9 ; P<0.0001\right)$, cover crop $\left(F_{1,14.1}=17.69 ; P=0.0001\right)$ and the interactions of year $\times$ cover crop $\left(F_{2,23}=7.28 ; P=0.0004\right)$ and year $\times$ cover crop $\times$ tillage $\left(F_{2,23}=4.5 ; P=0.022\right)$ significantly affected the activity-density of carabid beetles in $\mathrm{S} 1$ (Supplementary Table 4, Fig. 2a). In S2, year $\left(F_{2,2} 21.3\right.$ $=26.23 ; \quad P<0.0001)$, cover crop $\left(F_{1,11.1}=9.72 ; \quad P=\right.$ $0.010)$, and the interactions of year $\times$ tillage $\left(F_{2,21.3}=\right.$ 5.33; $P=0.013)$ and year $\times$ cover crop $\times$ tillage $\left(F_{2,21.3}=\right.$ 4.39; $P=0.025)$ significantly affected the activity-density of carabid species. In yr 3 of S1, activity-density of adult carabid beetles was significantly higher in RYE (40.2 \pm 4.76) compared with TIM $(20.0 \pm 2.5)$ (Fig. $2 a)$. No significant legacy effect of cover crops was observed for the evenness of the carabid beetle community. However, in the third year in S1, the carabid beetle community was marginally more even in the TIM $(0.71 \pm 0.05)$ than in the RYE treatments $(0.50 \pm 0.03)$ (year $\times$ cover, $P=0.069)$. Year in the crop sequence had a significant effect on richness $(\mathrm{S})$, evenness $\left(\mathrm{E}_{\mathrm{var}}\right)$ and diversity $\left(H^{\prime}\right)$ of carabid beetles in both Starts (Supplementary Table 4, Fig. 2).

In contrast to the lack of a legacy effect of cover crops on overall soil arthropod activity-densities, both PRC and RDA showed that cover crop was associated with the composition of the soil arthropod community. Based on the PRC, year in crop sequence and cover crop $\times$ tillage treatment interactions predicted community composition in both $\mathrm{S} 1$ (Fig. 3a; $F=6.5, P=0.0358$ ) and $\mathrm{S} 2$ (Fig. 3b;
$F=5.6, P=0.0136$ ). Soil arthropod community composition generally differed according to cover crop in yr 1, by an interaction of cover crop and tillage in yr 2 and by tillage intensity in yr 3, with little detectable legacy effect of the cover crop.

The RDAs confirmed the effects of initial cover crop on arthropod community composition (Fig. 4). Cover crop treatments were associated with the first axis in yr 1 accounting for $39.7 \%$ (S1) and $21.3 \%$ (S2) of the variance in the soil arthropod community. Efficiencies of the first and second axes were 79.64 and $38.5 \%$ in S1, and 57.06 and $15.27 \%$ in S2, respectively. In yr 1 of S1 (Fig. 4a), Collembola and Gryllidae were associated with RYE, whereas Araneae, Opiliones, Neuroptera larvae and ants (Formicidae) were associated with TIM. In yr 1 of S2, which had been maintained in the year preceding the beginning of the Start in timothy and red clover, Carabidae and Opiliones were associated with the RYE treatment, while Chrysomelidae (flea beetles), unidentified Coleoptera larvae, Lepidoptera larvae and Caelifera (grasshoppers) were associated with TIM (Fig. 4d). Environmental variables explained $20.4 \%$ (S1) and $12.9 \%$ (S2) of the variation in the soil arthropod community, but no single measured environmental variable contributed significantly to the variation in either Start according to interactive forward selection $\left(P_{\text {adj }}>0.05\right)$.

By the second year in the rotation, the association of cover crop and tillage treatments with the first two canonical axes was reduced, and effects on the soil arthropod groups began to shift from cover crop to tillage management (Fig $4 b$ and e). Efficiencies of the first 

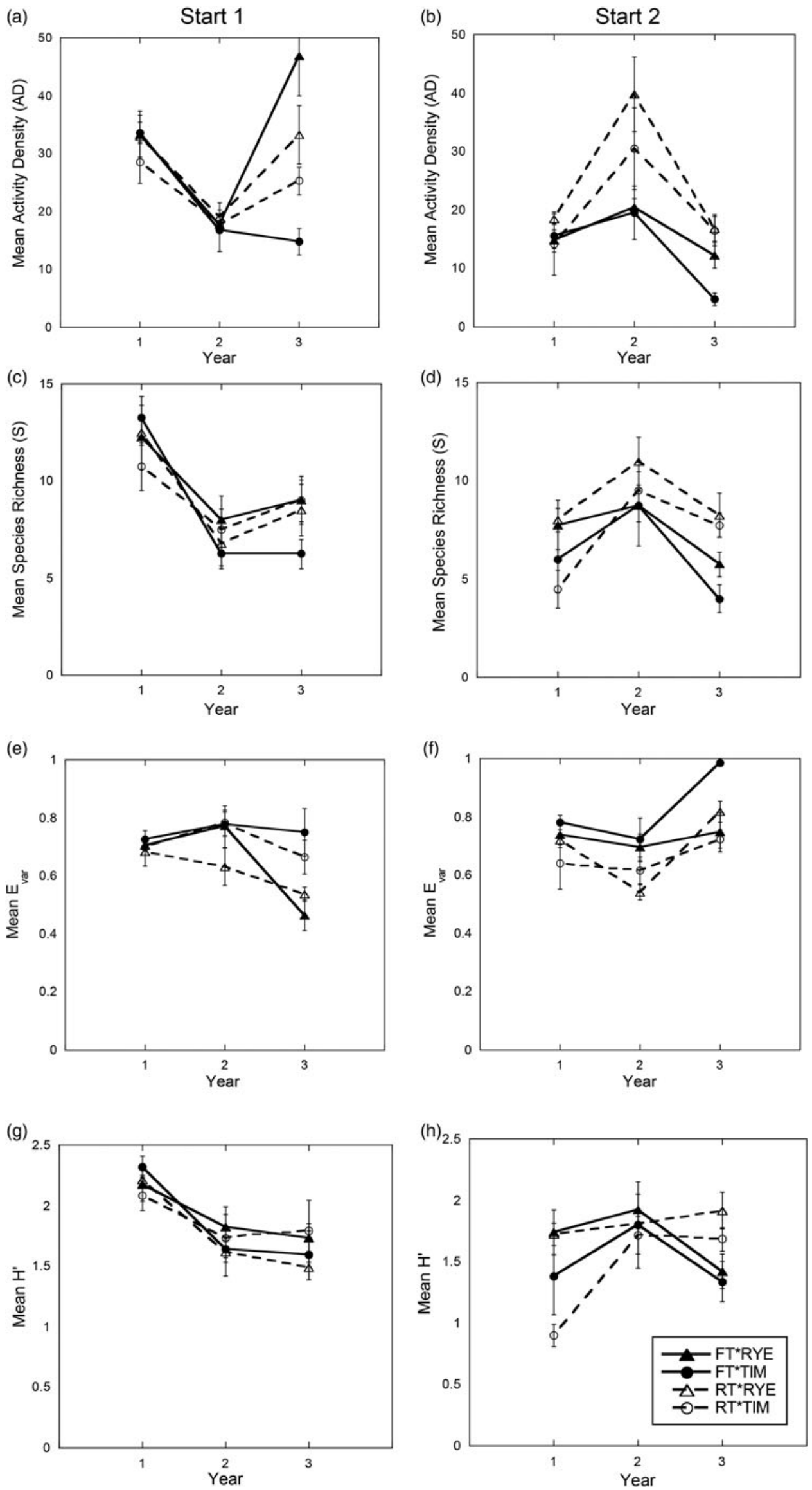

Figure 2. Change in mean ( \pm standard error) carabid beetle activity-density $(\mathrm{a}, \mathrm{b})$, evenness $\left(E_{\mathrm{var}}\right)(\mathrm{c}, \mathrm{d})$, species richness $(\mathrm{S})(\mathrm{e}, \mathrm{f})$, and Shannon-Wiener diversity $\left(\mathrm{H}^{\prime}\right)(\mathrm{g}, \mathrm{h})$ in the four cover crop and tillage treatment combinations in the two Starts of the 3-yr study. 

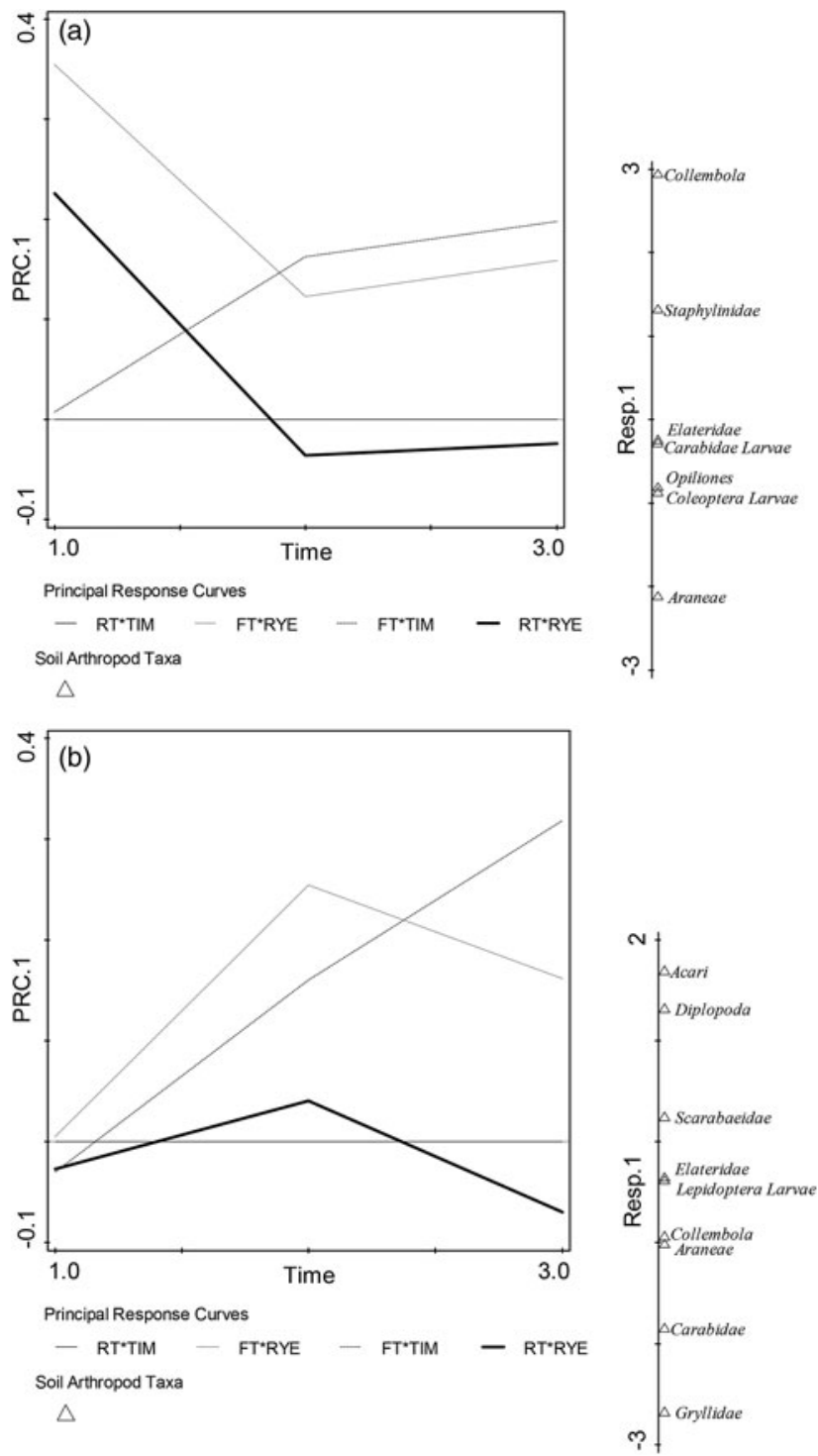

Figure 3. Soil arthropod principal response curves (PRCs) for Starts 1 (a) and 2 (b). In both Starts, the timothy/red clover $\times$ reduced tillage $(\mathrm{TIM} \times \mathrm{RT})$ treatment combination serves as the control, represented by a horizontal line. The species scores multiplied with the PRC scores represent the magnitude of difference of significant taxa in experimental treatments compared with the control. Inclusion rule for depiction on the diagrams is a fit to the model $\geq 10 \%$.

and second axes were 74.82 and $55.81 \%$ in S1, and 49.42 and $67.08 \%$ in S2, respectively. A legacy effect of RYE was observed for Scarabaeidae beetles and Formicidae ants in yr 2 of S1 and for Staphylinidae beetles in S2. In yr 2, environmental variables explained $26.3 \%$ (S1) and $29.0 \%$ (S2) of the variation in the soil arthropod community. Environmental variables that contributed to the variation in the soil arthropod community explained by environmental factors included percent soil organic matter $\left(14.1 \%\right.$; Pseudo- $F=2.7 ; \quad P_{\text {adj }}=$ $0.0396)$ and a non-significant trend for total weed density $\left(14.1 \%\right.$; Pseudo- $\left.F=2.8 ; \quad P_{\text {adj }}=0.0648\right)$ in $\mathrm{S} 1$ and soil electrical conductivity $(16.6 \%$; Pseudo- $F=3.3$; $\left.P_{\text {adj }}=0.0391\right)$ in $\mathrm{S} 2$.

In yr 3, the yr-1 cover crop had a weak effect on the composition of the soil arthropod community as evidenced by the second axis in the RDAs for both Starts, which explained only 9.9 and $6.88 \%$ of the variation in the soil arthropod community in S1 and S2, respectively (Fig 4c and f). In yr 3 of S1, a legacy effect of RYE on carabid beetles was observed, while in $\mathrm{S} 2$ carabid beetles were associated with RYE $\times$ RT and weed density. In the third year of the rotation, efficiencies of the first and second axes were 39.7 and $25.41 \%$ in S1, and 71.44 and $25.98 \%$ in S2, respectively. Environmental variables explained $26.1 \%(\mathrm{~S} 1)$ and $37.0 \%$ (S2) of the variation in soil arthropod taxa. Environmental variables that contributed significantly to the variation explained by environmental variables included percent soil organic matter $\left(17.5 \% ; F=2.3 ; P_{\text {adj }}=0.0078\right)$ and weed species richness $\left(12.4 \%\right.$; Pseudo- $\left.F=2.3 ; \quad P_{\text {adj }}=0.0184\right) \quad$ in $\mathrm{S} 1$, and soil $\mathrm{pH}\left(22.1 \%\right.$; Pseudo- $\left.F=4.0 ; \quad P_{\text {adj }}=0.009\right)$, total weed density $\left(16.0 \%\right.$; Pseudo- $\left.F=3.4 ; P_{\text {adj }}=0.0144\right)$ and soil sulfur concentration $(11.5 \%$; $\quad$ Pseudo- $F=2.7$; $\left.P_{\text {adj }}=0.0372\right)$ in $\mathrm{S} 2$.

\section{Effects of tillage on arthropod activity-density and community composition}

There were no significant differences in activity-densities due to tillage treatment for arthropods in general, or for carabid beetles, specifically (Supplementary Table 4). The effect of tillage on activity-densities of arthropods in S1 was not significant $\left(F_{1,3.33}=6.06 ; P=0.0825\right)$. Over the 3-yr transition, mean arthropod activitydensities ( \pm standard error) were $339.5 \pm 51.3$ and 239.6 \pm 33.8 in FT and RT treatments, respectively. Mean activity-densities per plot in S2 were $118.2 \pm 8.0$ and $111.3 \pm 7.2$ in FT and RT treatments, respectively. The effects of interactions of cover crop $\times$ tillage, and year $\times$ cover crop $\times$ tillage did not have a significant effect on general arthropod activity-density in either Start.

In contrast, interactions of tillage significantly affected the diversity indices of carabid beetles in S1 and S2 (Supplementary Table 4). In S1, activity-densities were similar between treatments until the third year, when average activity-density was significantly higher in FT $\times$ RYE $(46.75 \pm 6.86)$ and $\operatorname{RT} \times \operatorname{RYE}(33.25 \pm 5.03)$ in comparison with FT $\times$ TIM $(14.75 \pm 2.28)(\mathrm{FT} \times \mathrm{RYE}$ versus $\mathrm{FT} \times \mathrm{TIM}, P=0.001$; $\mathrm{RT} \times \mathrm{RYE}$ versus $\mathrm{FT} \times$ TIM, $P=0.0115$ ) (Fig. 2a, Supplementary Table 4). In S2, tillage $\times$ year $(P=0.013)$ and tillage $\times$ cover $\times$ year $(P=0.025)$ significantly affected carabid beetle activity density. Activity-density significantly declined in the third year of the rotation in FT treatments (yr 1 versus yr $3, P<0.01$ ). Meanwhile activity-density of Carabidae significantly increased in RT treatments from yr 1 to $\mathrm{yr}$ $2(P=0.0009)$, but declined in yr $3(P=0.0029)$. For 

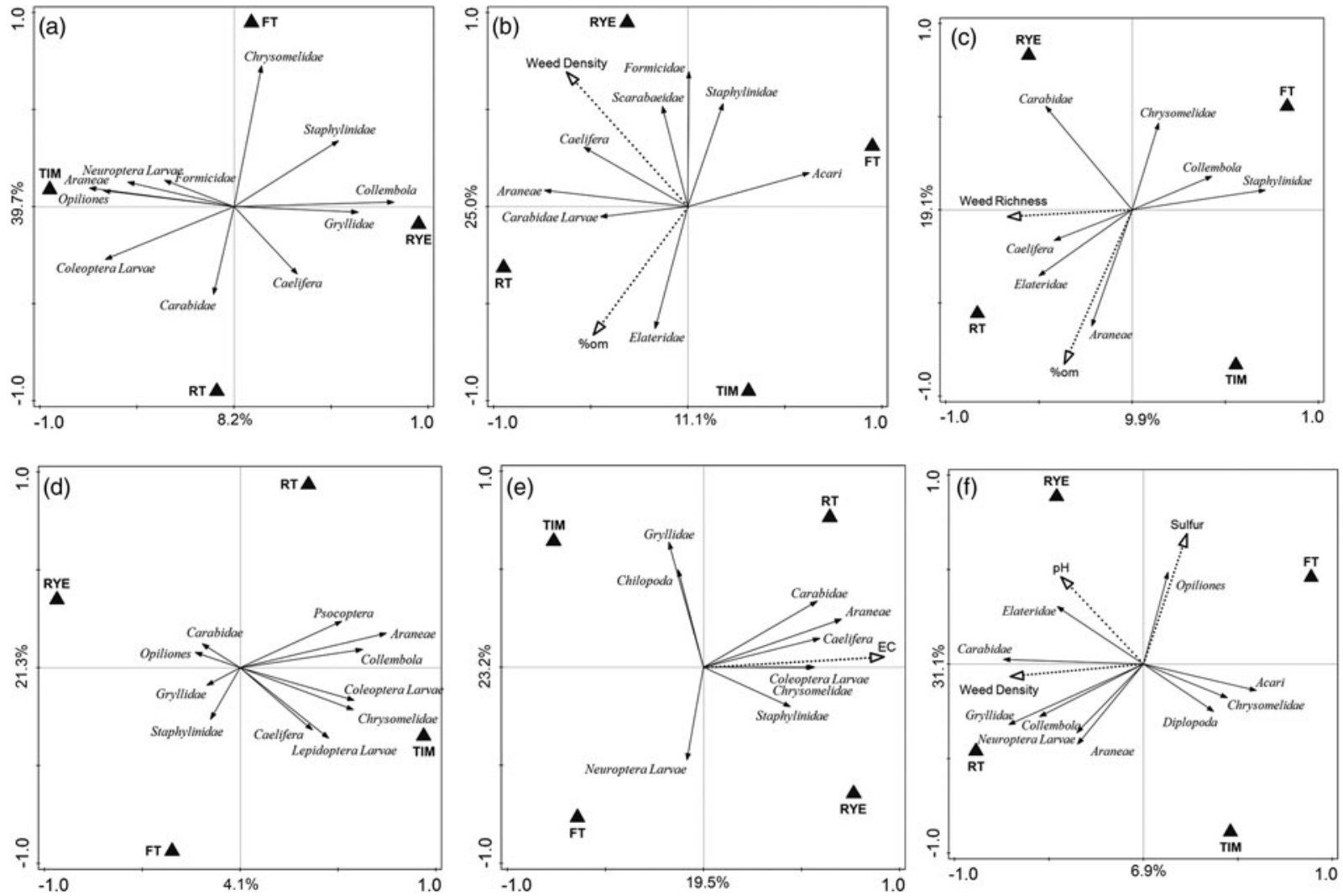

Figure 4. Biplots resulting from redundancy analyses for Start 1, yrs 1 (a), 2 (b), 3 (c), and Start 2, yrs 1 (d), 2 (e), 3 (f), respectively, and depicting associations between initial cover crop treatment (TIM, timothy/red clover mixture; and RYE, cereal rye followed by hairy vetch), tillage treatment (RT, reduced tillage; FT, full tillage) and soil arthropod taxa. Soil and weed measures with significant contribution to environmental variation that explains arthropod communities are projected onto the biplots as passive supplementary variables. Inclusion rule for depiction on biplots is a fit to the model $\geq 20 \%$.

community evenness, a different pattern emerged. On average, carabid communities were more even in the FT treatments $\left(e_{\mathrm{var}}=0.78\right)$ in comparison with RT $\left(e_{\mathrm{var}}=\right.$ 0.67) $(P=0.042)$ and in particular, in the third year of the FT $\times$ TIM treatment where $e_{\text {var }}$ reached $0.98 \pm 0.014$ (Fig. 2d, Supplementary Table 4 ). There was a non-significant trend $(P=0.058)$ for a year $\times$ tillage interaction on diversity $\left(H^{\prime}\right)$ of carabids in S2. By the third year of the sequence, the mean $H^{\prime}$ was higher in RT $(1.80 \pm 0.092)$ in comparison with FT treatments $(1.38 \pm 0.101 \mathrm{SE})$ (Fig. 2h, Supplementary Table 4).

PRCs and RDAs revealed the effect of tillage treatment on the composition of the soil arthropod community (Figs 3 and 4). PRC scores for Collembola, Acari, Staphylinidae and Chrysomelidae adults (flea beetles) in S1, and for Diplopoda, Acari, Scarabaeidae adults in S2 were associated with FT treatments. Three groups of predators (Araneae, Opiliones and Carabidae) had PRC scores associated with RT in S1. Two groups of predators (Araneae and Carabidae) and a granivore/scavenger (Gryllidae) had higher PRC scores in RT compared with FT treatments in S2. In S1, soil arthropods most closely associated with RT included herbivorous Elateridae beetles and grasshoppers (Caelifera). Arthropods most closely associated with FT included collembolans and Staphylinidae beetles (Fig. 3).

\section{Discussion}

Initial cover crop species, soil management and year in which the transition to organic production is initiated affected the composition of the soil-associated arthropod community, and activity-density and diversity of Carabidae beetles, of particular interest because of their beneficial functions in agroecosystems. Overall, initial cover crop had the greatest influence on arthropods in the first year of the transition, but by the final year of the transition sequence, tillage intensity more strongly differentiated soil arthropod communities. The shift from the influence of initial cover crop to tillage was reflected by an interaction between cover crop and tillage intensity in the second year. We observed few legacy effects of initial cover crop, although exceptions to this pattern occurred in cereal rye treatments. In yr 2 we observed a legacy effect for Scarabaeidae, Staphylinidae and Formicidae, and in yr 3, for carabid beetles. 
Cover crops are a common feature of organic farming systems, and their residues add spatial, temporal, taxonomic and functional diversity to agricultural systems (Clark, 2007). Different types of cover crops and residues can harbor distinctive complexes of arthropods and can have significant positive or negative impacts on crop yield and quality (Booij and Noorlander, 1992; Baggen et al., 1999; Tillman et al., 2004; Gallandt et al., 2005; Lundgren and Fergen, 2011; Carr et al., 2013). Residue produced by cover crops can leave a legacy of effects that remain after the management practices have been discontinued (Davis et al., 2009; Lundgren and Fergen, 2011). For example, Lundgren and Fergen (2011) found greater predation of the western corn rootworm, Diabrotica virgifera virgifera, in maize following an overwintering cover crop of slender wheat grass, Elymus trachycaulus, than when maize followed a fallow period. In the second year of our experiment, soil arthropods in reduced tillage treatments may have been influenced by the rolled cover crop mulch that remained on the soil surface. Surface mulch can yield a distinctive habitat for ground-dwelling arthropods by altering light availability and other microclimate variables (Mirsky et al., 2012; Carr et al., 2013) and by providing resources for arthropods and their natural enemies (Landis et al., 2000, 2005). A killed cover crop mulching system in sweet potatoes supported a higher number of carabid beetles, staphylinid beetles and fire ants in comparison with treatments without cover crop residue (Jackson and Harrison, 2008).

In full tillage systems, incorporation of green manures and crop residues can result in positive cascading effects on disturbance-adapted mites and collembolans in the decomposer food web (Sabatini et al., 1997; Birkhofer et al., 2008; Von Berg et al., 2010; Dominguez et al., 2014). In our experiment, collembolans and mites comprised the greatest numbers of arthropods captured in pitfall traps in all treatments. We hypothesize that the legacy effects that we observed for the cereal rye treatment on carabid and staphylinid beetles, and ants were mediated by undecomposed residues of cereal rye on the surface in the reduced tillage treatment, and by subsidies to microarthropod populations in full tillage treatments.

Carabid beetles were the only soil arthropod group for which we observed a legacy effect of cover crop in the third year. In Start 1, activity-densities of carabid beetles were higher in treatments in which cereal rye was the initial cover crop compared with those initiated with timothy. Weed density was associated with the cereal rye in yr 2 in Start 1 and with reduced tillage $x$ cereal rye in yr 3 in Starts 1 and 2, and weeds may have contributed to the higher activity-density and diversity of carabids (Pavuk et al., 1997; Pfiffner and Luka, 2003). Furthermore, in cereal rye treatments, volunteer cereal rye was apparent in yrs 2 and 3 (Smith et al., 2011). A legacy effect of cover crop on carabids may have been due in part to cereal rye grain residue serving as a resource for omnivorous or granivorous carabid beetles directly or carnivorous carabids indirectly via a granivorous prey group, such as earthworms, crickets or slugs (Gallandt et al., 2005; Lundgren, 2009). In one study, omnivorous carabids showed greater aggregation and decreased emigration in response to seed subsidies compared with larval prey (Frank et al., 2011).

Organic farming practices can lead to changes in species evenness (Crowder et al., 2012). In our study, the carabid beetle community was significantly more even in timothy treatments than in the cereal rye treatments in Start 1 (cover crop, $P=0.014$ ), but there was no significant legacy effect of cover crop on carabid beetle eveness (year $\times$ cover crop, $P=0.069$ ). In contrast, carabid beetle richness and Shannon diversity in Start 2 were more responsive to tillage than to initial cover crop, and both indices increased in the reduced tillage treatments over the transition period. These results support the assertion of Crowder et al. (2010, 2012), that richness and evenness each require individual attention to understand the effects of particular practices on biodiversity and biodiversity-related services. Evenness has been associated with improved ecosystem services such as pollination (Ghazoul, 2006) and biological control (Crowder et al., 2010) when that service is dependent on the collective action of the community (Hillebrand et al., 2008).

Soil- and litter-inhabiting arthropod predators, especially carabid beetles and spiders, often increase as tillage is reduced (Stinner and House, 1990). Lundgren et al. (2006) examined the effects of frequency and intensity of soil disturbance during the transition period on carabid beetles and spiders, and observed that densities of these beneficial arthropods were higher in low- compared with high-management-intensity systems. They concluded that the habitat stability associated with lowintensity systems favors beneficial ground-dwelling arthropod communities during the transition. We did not observe any strong or consistent effects of tillage regimen on overall soil arthropod activity-density, but did observe effects of tillage on soil arthropod community composition. Perhaps non-inversion tillage with a chisel plow in reduced tillage treatments and inversion tillage with a moldboard plow in the full tillage treatment in our study did not represent a large enough contrast in soil disturbance to result in significant effects on arthropod activity-density. In contrast, carabid beetle activitydensity, species richness and Shannon-Wiener diversity were higher in reduced tillage treatments in comparison with full tillage treatments in yr 3 of Start 2.

Weed density contributed to variation in soil arthropod community composition, with weed measures contributing from 12 to $16 \%$ of the variation due to environmental effects in yr 3 . Although a major constraint in organic crop production (Bond and Grundy, 2001), weeds can be important components of the agroecosystem and may exert influence at multiple trophic levels (Evans et al., 2011). 
Weeds can benefit predaceous and parasitic arthropods by providing resources such as prey and non-prey foods, overwintering sites, favorable microclimates and preferred oviposition sites that are often reduced or removed in annual cropping systems in which weed suppression is optimal (Landis et al., 2005; Lundgren, 2009; Evans et al., 2011). Weed density and diversity increased over the course of our transition experiment in all treatments, and the density of weeds emerging from the existing seed bank was $82 \%$ greater in reduced- than in full-tillage treatments during the second year in Start 1, and about 244\% greater in reduced- than in full-tillage treatments in yr 3 in both Starts (Smith et al., 2011).

Our results suggest that initial conditions during the transition may affect the predictability of the outcomes of management treatments. The year in which we initiated the experiment (Start) had a strong effect on our results. Experimental Starts were offset by only $1 \mathrm{yr}$, and conducted on adjoining fields that had been under homogeneous management in the years preceding our experiment. Even so, experimental Start had a pervasive influence on soil (Lewis et al., 2011), soil biota (Jabbour and Barbercheck, 2009), weed, yield and profitability measures (Smith et al., 2011). In the year before initiating Start 2, the field was planted with timothy, oats and red clover. Thus, Start 2 experienced no soil disturbance for 2 yrs before soybean planting in contrast to $1 \mathrm{yr}$, as in Start 1. Lewis et al. (2011) hypothesized that the influence of Start may have resulted from differences between the initial soil conditions due to the extra cover crop year in Start 2.

We expected that activity-densities of arthropods in Start 2 would be greater than in Start 1 due to the longer period without soil disturbance before the start of the experiment (Lundgren et al., 2006). However, activity-densities for most arthropod groups were lower in Start 2 than in Start 1. In Start 1, a pattern of increasing arthropod activity-density during the 3-yr transition was driven by collembolans, the most frequently observed arthropod group. Spiders and carabid beetles followed the same general pattern. Collembolans are an important prey group for generalist arthropod predators and can contribute to the increase in their numbers (Bilde et al., 2000; Halaj and Wise, 2002). However, in Start 2, collembolan activity-density was only one-third of that observed for Start 1, and did not increase over the transition period.

This study shows the linkage between management practices and inter-annual variation in arthropod activitydensity, community composition and carabid beetle diversity within an organic production system that differed in initial cover crop and tillage regimen. Although intraannual practices affected many of the responses, we also observed an inter-annual legacy effect of initial cover crop for scarab and staphylinid beetles and ants in the year following the cover crop year, and for carabid beetles that was still apparent 2 yrs after termination of the cover crop. Multiple habitat characteristics changed over time in conjunction with the treatments and depending on the timing and intensity of disturbance, including weed diversity, density and phenology (Smith et al., 2011), the amount of plant residues on the soil surface and soil characteristics (Lewis et al., 2011). The relatively high proportions of predators captured in pitfall traps, and a general observation of a lack of crop damage by pests in this experiment (Letourneau et al., 2009), suggest that the level of biological control of pest arthropods should be evaluated in future experiments (Bengtsson et al., 2005; Hole et al., 2005; Birkhofer et al., 2008; Crowder et al., 2010, 2012). Our observations on cover crop legacy and weed effects for some predatory arthropod groups support the concept that both immediate and longer-term effects of management shape arthropod communities during the organic transition period. The presence of weeds and cover crop residues, whether left on the surface or incorporated into the soil, can enhance the biotic and abiotic environment to conserve arthropod natural enemy communities.

\section{Supplementary Material}

For supplementary material accompanying this paper, visit http://dx.doi.org/10.1017/S1742170515000290

Acknowledgements. We thank S. Harkcom, D. Heggenstaller, V. Houck, B. Jones, S. Kinneer, C. Nardozzo, D. Sandy, and S. Smiles for providing technical assistance, and many undergraduate students who diligently sorted insects. We gratefully acknowledge the advice provided by our advisory board: C. Altemose, L. Garling, J. Moyer, B. Snyder, K. Yoder, P. Yoder, A. Ziegler and L. Zuck. Funding for this research was provided by the USDA NIFA Competitive Grants Program-IPM-ORG-112.E.

\section{References}

Baggen, L.R., Gurr, G.M., and Meats, A. 1999. Flowers in tritrophic systems: Mechanisms allowing selective exploitation by insect natural enemies for conservation biological control. Entomologia Experimentalis et Applicata 91:155-161.

Bengtsson, J., Ahnstrom, J., and Weibull, A. 2005. The effects of organic agriculture on biodiversity and abundance: A metaanalysis. Journal of Applied Ecology 42:261-269.

Bilde, T., Axelsen, J.A., and Toft, S. 2000. The value of Collembola from agricultural soils as food for a generalist predator. Journal of Applied Ecology 37:672-683.

Birkhofer, K., Bezemer, T.M., Bloem, J., Bonkowski, M., Christensen, S., Dubois, D., Ekelund, F., Fließbach, A., Gunst, L., Hedlund, K., Mäder, P., Mikola, J., Robin, C., Setälä, H., Tatin-Froux, F., Van der Putten, W.H., and Scheu, S. 2008. Long-term organic farming fosters below and aboveground biota: Implications for soil quality, biological control and productivity. Soil Biology and Biochemistry 40:2297-2308. 
Bohan, D.A., Boursault, A., Brooks, D.R., and Petit, S. 2011. National-scale regulation of the weed seedbank by carabid predators. Journal of Applied Ecology 48:888-898.

Bond, W. and Grundy, A.C. 2001. Non-chemical weed management in organic farming systems. Weed Research VV:383-405.

Booij, C. and Noorlander, J. 1992. Farming systems and insect predators. Agriculture, Ecosystems \& Environment 40:125-135.

Bourassa, S., Cárcamo, H.A., Larney, F.J., and Spence, J.R. 2008. Carabid assemblages (Coleoptera: Carabidae) in a rotation of three different crops in southern Alberta, Canada: a comparison of sustainable and conventional farming. Environmental Entomology 37:1214-1223.

Braker, W.L. 1981. Soil Survey of Centre County, Pennsylvania. USDA-SCS, Washington, DC.

Cambardella, C.A. and Elliott, E.T. 1992. Particulate soil organic-matter changes across a grassland cultivation sequence. Soil Science Society of America Journal 56:777-783.

Carmona, D.M. and Landis, D.A. 1999. Influence of refuge habitats and cover crops on seasonal activity-density of ground beetles (Coleoptera: Carabidae) in field crops. Environmental Entomology 28:1145-1153.

Carr, P., Gramig, G., and Liebig, M. 2013. Impacts of organic zero tillage systems on crops, weeds, and soil quality. Sustainability 5:3172-3201.

Cavigelli, M.A., Mirsky, S.B., Teasdale, J.R., Spargo, J.T., and Doran, J. 2013. Organic grain cropping systems to enhance ecosystem services. Renewable Agriculture and Food Systems 28:145-159.

Ciegler, J. and Morse, J. 2000. Ground Beetles and Wrinkled Bark Beetles of South Carolina (Coleoptera: Geadephaga: Carabidae and Rhysodidae). Clemson University, Clemson, SC.

Clark, A. 2007. Managing Cover Crops Profitably, 3rd ed. Sustainable Agriculture Network, Beltsville, MD.

Clark, S., Szlavecz, K., Cavigelli, M.A., and Purrington, F. 2006. Ground beetle (Coleoptera: Carabidae) assemblages in organic, no-till, and chisel-till cropping systems in Maryland. Environmental Entomology 35:1304-1312.

Crowder, D.W., Northfield, T.D., Gomulkiewicz, R., and Snyder, W.E. 2012. Conserving and promoting evenness: Organic farming and fire-based wildlife management as case studies. Ecology 93:2001-2007.

Crowder, D.W., Northfield, T.D., Strand, M.R., and Snyder, W.E. 2010. Organic agriculture promotes evenness and natural pest control. Nature 466:109-112.

Culman, S.W., Snapp, S.S., Freeman, M.A., Schipanski, M.E., Beniston, J., Lal, R., Drinkwater, L.E., Franzluebbers, A.J., Glover, J.D., Grandy, A.S., Lee, J., Six, J., Maul, J.E., Mirksy, S.B., Spargo, J.T., and Wander, M.M. 2012. Permanganate oxidizable carbon reflects a processed soil fraction that is sensitive to management. Soil Science Society of America Journal 76:494-504.

Davis, H.N., Currie, R.S., Wade French, B., and Buschman, L.L. 2009. Impact of land management practices on carabids (Coleoptera: Carabidae) and other arthropods on the Western High Plains of North America. Southwestern Entomologist 34:43-59.

De Ponti, T., Rijk, B., and van Ittersum, M.K. 2012. The crop yield gap between organic and conventional agriculture. Agricultural Systems 108:1-9.

Diehl, E., Wolters, V., and Birkhofer, K. 2012. Arable weeds in organically managed wheat fields foster carabid beetles by resource- and structure-mediated effects. Arthropod Plant Interactions 6:75-82.

Dominguez, A., Bedano, J.C., Becker, A.R., and Arolfo, R.V. 2014. Organic farming fosters agroecosystem functioning in Argentinian temperate soils: Evidence from litter decomposition and soil fauna. Applied Soil Ecology 83:170-176.

Downie, N.M. and Arnett, J.R.H. 1996. The Beetles of Northeastern North America, Volume 1. The Sandhill Crane Press, Gainesville, FL.

Evans, D.M., Pocock, M.J.O., Brooks, J., and Memmott, J. 2011. Seeds in farmland food-webs: Resource importance, distribution and the impacts of farm management. Biological Conservation 144:2941-2950.

Frank, S.D., Shrewsbury, P.M., and Denno, R.F. 2011. Plant versus prey resources: Influence on omnivore behavior and herbivore suppression. Biological Control 57:229-235.

Gallandt, E.R., Molloy, T., Lynch, R.P., and Drummond, F.A. 2005. Effect of cover-cropping systems on invertebrate seed predation. Weed Science 53:69-76.

Ghazoul, J. 2006. Floral diversity and the facilitation of pollination. Journal of Ecology 94:295-304.

Gregorich, E.G. and Janzen, H.H. 1996. Storage of soil carbon in the light fraction and macro organic matter. In M.R. Carter and B.A. Stewart (eds.). Structure and Soil Organic Matter Storage in Agricultural Soils. Lewis Publishers, CRC Press, Boca Raton, FL. p. 167-190.

Halaj, J. and Wise, D.H. 2002. Impact of a detrital subsidy on trophic cascades in a terrestrial grazing food web. Ecology 83:3141-3151.

Hatten, T.D., Bosque-Pérez, N.A., Johnson-Maynard, J., and Eigenbrode, S.D. 2007. Tillage differentially affects the capture rate of pitfall traps for three species of carabid beetles. Entomologia Experimentalis et Applicata 124:177-187.

Hillebrand, H., Bennett, D.M., and Cadotte, M.W. 2008. Consequences of dominance: A review of evenness effects on local and regional ecosystem processes. Ecology 89: 1510-1520.

Hole, D.G., Perkins, A.J., Wilson, J.D., Alexander, I.H., Grice, P.V., and Evans, A.D. 2005. Does organic farming benefit biodiversity? Biological Conservation 122:113-130.

Honek, A. and Jarosik, V. 2000. The role of crop density, seed and aphid presence in diversification of field communities of Carabidae (Coleoptera). European Journal of Entomology 97:517-525.

Honek, A., Matinkova, Z., and Jarosik, V. 2003. Ground beetles (Carabidae) as seed predators. European Journal of Entomology 100:531-544.

Jabbour, R. and Barbercheck, M.E. 2009. Soil management effects on entomopathogenic fungi during the transition to organic agriculture in a feed grain rotation. Biological Control 51:435-443.

Jackson, D.M. and Harrison, H.F. 2008. Effects of a killed-cover crop mulching system on sweetpotato production, soil pests, and insect predators in South Carolina. Journal of Economic Entomology 101:1871-1880.

Kromp, B. 1999. Carabid beetles in sustainable agriculture: A review on pest control efficacy, cultivation impacts and enhancement. Agriculture, Ecosystems \& Environment 74: 187-228.

Landis, D.A., Menalled, F.D., Costamagna, A.C., and Wilkinson, T.K. 2005. Manipulating plant resources to 
enhance beneficial arthropods in agricultural landscapes Weed Science 53:902-908.

Landis, D.A., Wratten, S.D., and Gurr, G.M. 2000. Habitat management to conserve natural enemies of arthropod pests in agriculture. Annual Review of Entomology 45:175-201.

Leslie, T.W., Hoheisel, G.A., Biddinger, D.J., Rohr, J.R., and Fleischer, S.J. 2007. Transgenes sustain epigeal insect biodiversity in diversified vegetable farm systems. Environmental Entomology 36:234-244.

Letourneau, D.K., Jedlicka, J.A., Bothwell, S.G., and Moreno, C.R. 2009. Effects of natural enemy biodiversity on the suppression of arthropod herbivores in terrestrial ecosystems. Annual Review of Ecology, Evolution, and Systematics 40:573-592.

Lewis, D.B., Kaye, J.P., Jabbour, R., and Barbercheck, M.E. 2011. Labile carbon and other soil quality indicators in two tillage systems during transition to organic agriculture. Renewable Agriculture and Food Systems 26:342-353.

Lundgren, J. 2009. Relationship of Natural Enemies and NonPrey Foods. Springer Verlag, Dordrecht.

Lundgren, J.G. and Fergen, J.K. 2011. Enhancing predation of a subterranean insect pest: A conservation benefit of winter vegetation in agroecosystems. Applied Soil Ecology 51:9-16.

Lundgren, J.G., Duan, J.J., Paradise, M.S., and Wiedenmann, R. N. 2005. Rearing protocol and life history traits for Poecilus chalcites. Journal of Entomological Science 40:126-135.

Lundgren, J.G., Shaw, J.T., Zaborski, E.R., and Eastman, C.E. 2006. The influence of organic transition systems on beneficial ground-dwelling arthropods and predation of insects and weed seeds. Renewable Agriculture and Food Systems 21:227-237.

Mäder, P., Fliessbach, A., Dubois, D., Gunst, L., Fried, P., and Niggli, U. 2002. Soil fertility and biodiversity in organic farming. Science 296:1694-1697.

Marshall, S.A. 2006. Insects: Their History and Diversity. Firefly Books, Inc., Buffalo, NY.

Maxwell, B.D., Smith, R.G., and Brelsford, M. 2007. Wild oat (Avena fatua) seed bank dynamics in transition to organic wheat production systems. Weed Science 55:212-217.

Mccravey, K.W. and Lundgren, J.G. 2011. Carabid beetles (Coleoptera: Carabidae) of the Midwestern United States: A review and synthesis of recent research. Terrestrial Arthropod Reviews 4:63-94.

Melnychuk, N., Olfert, O., Youngs, B., and Gillott, C. 2003. Abundance and diversity of Carabidae (Coleoptera) in different farming systems. Agriculture, Ecosystems \& Environment 95:69-72.

Menalled, F., Marino, P.C., Renner, K.A., and Landis, D.A. 2000. Post-dispersal weed seed predation in Michigan crop fields as a function of agricultural landscape structure. Agriculture, Ecosystems \& Environment 77:193-202.

Menalled, F.D., Smith, R.G., Dauer, J.T., and Fox, T.B. 2007. Impact of agricultural management on carabid communities and weed seed predation. Agriculture, Ecosystems \& Environment 118:49-54.

Mirsky, S.B., Ryan, M.R., Curran, W.S., Teasdale, J.R., Maul, J., Spargo, J.T., Moyer, J., Grantham, A.M., Weber, D., Way, T.R., and Camargo, G.G. 2012. Conservation tillage issues: Cover crop-based organic rotational no-till grain production in the mid-Atlantic region, USA. Renewable Agriculture and Food Systems 27:31-40.

Morrill, W.L. 1975. Plastic pitfall trap. Environmental Entomology 4:596.
O'Rourke, M.E., Liebman, M., and Rice, M.E. 2008. Ground beetle (Coleoptera : Carabidae) assemblages in conventional and diversified crop rotation systems. Environmental Entomology 37:121-130.

OFRF 1998. Third Biennial National Organic Farmer's Survey. Organic Farming Research Foundation, Santa Cruz, CA.

Pavuk, D.M., Purrington, F.F., Williams, C.E., and Stinner, B.R. 1997. Ground beetle (Coleoptera: Carabidae) activity density and community composition in vegetationally diverse corn agroecosystems. American Midland Naturalist 138:14-28.

Pereira, J.L., Picanço, M.C., Pereira, E.J.G., Silva, A.A., Jakelaitis, A., Pereira, R.R., and Xavier, V.M. 2010. Influence of crop management practices on bean foliage arthropods. Bulletin of Entomological Research 100:679-688.

Pfiffner, L. and Luka, H. 2003. Effects of low-input farming systems on carabids and epigeal spiders - a paired farm approach. Basic and Applied Ecology 127:117-127.

Prasifka, J.R., Schmidt, N.P., Kohler, K.A., O’Neal, M.E., Hellmich, R.L., and Singer, J.W. 2006. Effects of living mulches on predator abundance and sentinel prey in a corn-soybean-forage rotation. Environmental Entomology 35:1423-1431.

Pullaro, T.C., Marino, P.C., Jackson, D.M., Harrison, H.F., and Keinath, A.P. 2006. Effects of killed cover crop mulch on weeds, weed seeds, and herbivores. Agriculture, Ecosystems \& Environment 115:97-104.

Purtauf, T., Roschewitz, I., Dauber, J., Thies, C., Tscharntke, T., and Wolters, V. 2005. Landscape context of organic and conventional farms: Influences on carabid beetle diversity. Agriculture, Ecosystems \& Environment 108:165-174.

Purvis, G., Fadl, A., and Bolger, T. 2001. A multivariate analysis of cropping effects on Irish ground beetle assemblages (Coleoptera: Carabidae) in mixed arable and grass farmland. Annals of Applied Biology 139:351-360.

Sabatini, M.A., Rebecchi, L., Cappi, C., Bertolani, R., and Fratello, B. 1997. Long-term effects of three different continuous tillage practices on Collembola populations. Pedobiologia 41:185-193.

SAS Institute. 2004. SAS 9.1.3 Help and Documentation. SAS Institute, Inc., Cary, NC.

Shannon, C.E. 1948. A mathematical theory of communication. Bell System Technical Journal 27:379-423.

Shearin, A.F., Reberg-Horton, C.S., and Gallandt, E.R. 2008. Cover crop effects on the activity-density of the weed seed predator Harpalus rufipes (Coleoptera: Carabidae). Weed Science 56:442-450.

Shennan, C. 2008. Biotic interactions, ecological knowledge and agriculture. Philosophical Transactions of the Royal Society of London Series B 363:717-739.

Šmilauer, P. and Lepš, J. 2014. Multivariate Analysis of Ecological Data using Canoco 5. Cambridge University Press, Cambridge, UK.

Smith, B. and Wilson, J.B. 1996. A consumer's guide to evenness indices. Oikos 76:70-82.

Smith, R.G., Jabbour, R., Hulting, A.G., Barbercheck, M.E., and Mortensen, D.A. 2009. Effects of initial seed-bank density on weed seedling emergence during the transition to an organic feed-grain crop rotation. Weed Science 57:533-540.

Smith, R.G., Barbercheck, M.E., Mortensen, D.A., Hyde, J., and Hulting, A.G. 2011. Yield and net returns during the transition to organic feed grain production. Agronomy Journal 103:51-59. 
Stinner, B.R. and House, G. 1990. Arthropods and other invertebrates in conservation-tillage agriculture. Annual Review of Entomology 35:299-318.

Stokes, M.E., Davis, C.S., and Koch, G.G. 2000. Categorical Data Analysis Using the SAS System. 2nd ed. SAS Institute, Inc., Cary, NC.

terBraak, C. and Šmilauer, P. 2012. CANONO Reference Manual and User's Guide. Canoco 5.0. Biometris, Wageningen.

Tillman, G., Schomberg, H., Phatak, S., Mullinix, B., Lachnicht, S., Timper, P., and Olson, D. 2004. Influence of cover crops on insect pests and predators in conservation tillage cotton. Journal of Economic Entomology 97:1217-1232.
Von Berg, K., Thies, C., Tscharntke, T., and Scheu, S. 2010. Changes in herbivore control in arable fields by detrital subsidies depend on predator species and vary in space. Oecologia 163:1033-1042.

Weil, R.R., Islam, K.R., Stine, M.A., Gruver, J.B., and Samson-Liebig, S.E. 2003. Estimating active carbon for soil quality assessment: A simplified method for laboratory and field use. American Journal of Alternative Agriculture 18:3-17.

Zehnder, G., Gurr, G.M., Kühne, S., Wade, M.R., Wratten, S.D., and Wyss, E. 2007. Arthropod pest management in organic crops. Annual Review of Entomology 52:57-80. 